\title{
Extra-oral Mandibular Nerve Block Comparative Evaluation of Local Anesthetic Distribution Using Ultrasonography
}

\section{THESIS}

Presented in Partial Fulfillment of the Requirements for the Degree Master of Science in the Graduate School of The Ohio State University

By

Sara Margit Abbott Weinstein, DDS

Graduate Program in Dentistry

The Ohio State University

2014

Master's Examination Committee:

Dr. Simon Prior, Adviser

Dr. William M. Johnston

Dr. Melissa Drum 


\section{Copyright by}

Sara Margit Abbott Weinstein, DDS

2014 


\begin{abstract}
The incidence of failure to achieve pulpal anesthesia of the mandibular teeth using the traditional techniques is quite high. Failure rates have been reported by several authors to be $15-20 \%{ }^{1}$. As a result there is continued interest in striving for an alternative mandibular nerve block offering the potential of greater success. In dentistry, mandibular nerve blocks are commonly performed using an intra-oral, open-mouth technique while other areas of medicine typically use an extra-oral technique. The lesser-used AkinosiVazirani technique is a closed-mouth, intra-oral technique; an interesting alternative to the Halstead used also for achieving a mandibular nerve block. The goals of these injection techniques are to place local anesthetic solution adjacent to the mandibular or alveolar nerves. $^{2}$ The Akinosi-Vazirani technique has been shown to have both higher and comparable success rates when compared to the Halstead technique ${ }^{2}$. The goal of an alternative extra-oral, closed-mouth technique by Kantorowicz is also to deliver local anesthesia adjacent to the mandibular foramen. This technique offers a number of additional benefits such as reducing the need for patient cooperation and as the path of injection also more closely approximates that of the nerve itself it may offer a better contact between local anesthetic solution and nerve trunk. If the Kantorowicz technique can be shown to reliably deliver local anesthetic solution within the ptergyomandibular space adjacent to the mandibular foramen it may achieve comparable or superior
\end{abstract}


anesthesia of mandibular teeth. Such an alternative could then be a valuable and routine adjunct to be taught to dental students for use in dental practice. 


\section{Dedication}

This document is dedicated to my husband, Michael, for without you this journey would have been far more difficult and not nearly as much fun. 


\section{Acknowledgements}

There are many individuals I would like to thank for their contributions to this

thesis. First, I would like to thank my advisor, Dr. Simon Prior, for his knowledge, encouragement, and patience. I have learned very much from him and am grateful for his support during my residency.

I also would like to thank my other master's committee members: Dr. Johnston and Dr. Drum. I'd like to thank Dr. William M. Johnston for his immense knowledge on statistics. I am grateful for all of the time he spent helping me and for his kindness and patience. I'd also like to thank Dr. Melissa Drum for her willingness to help with this thesis and for the encouragement and help she provided me.

Additionally, I would like to thank Drs. Larsen, Ness, Emam, Kennedy, and Jatana who have served as instructors, advisors, and mentors throughout residency.

Lastly, I would like to thank the many residents I have had the pleasure of knowing and working with over the last four years. 


\section{Vita}

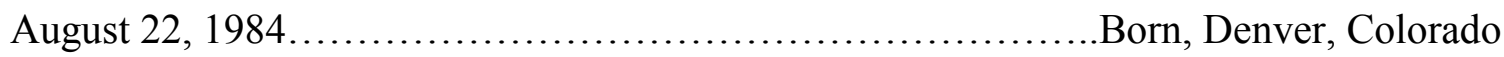

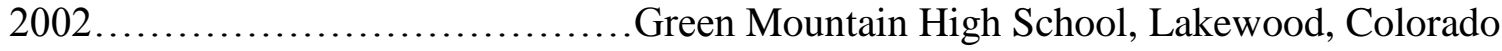
2006.......................... Biology, Quinnipiac University, Hamden, Connecticut 2010......................D.D.S. University of Colorado School of Dental Medicine 2010 to present …........................................MFS Resident, The Ohio State University, Columbus, Ohio

\section{Publications}

Abbott SM and G.K. Wong. The conditioning and memory retention of planaria (Dugesia tigrina) for directional preferences. BIOS. 79(4) 160-174. 2008

Malamed, S.F. Sedation: A Guide to Patient Management. $5^{\text {th }}$ edition. 2009. Assisted Dr. Morris Clark with 8 chapters of inhalation sedation.

\section{Fields of Study}

Major Field: Dentistry

Specialization: Oral and Maxillofacial Surgery 


\section{Table of Contents}

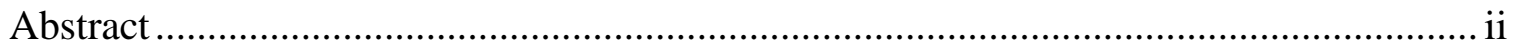

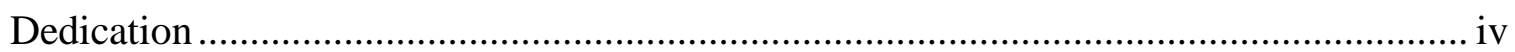

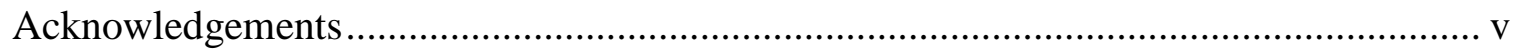

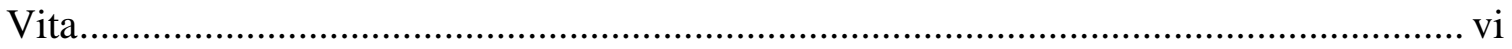

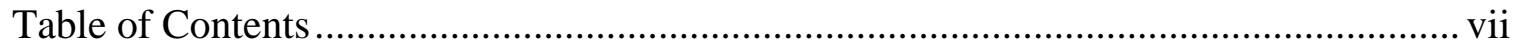

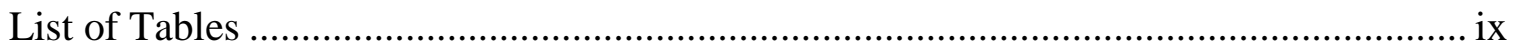

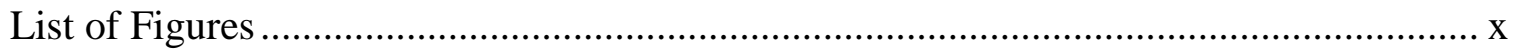

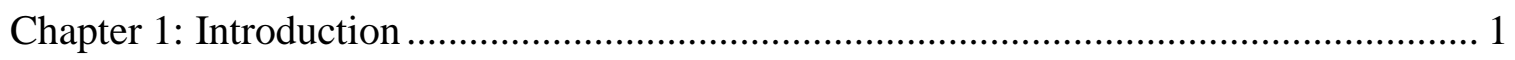

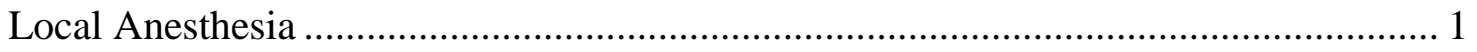

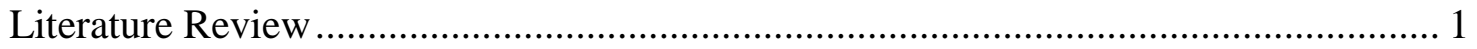

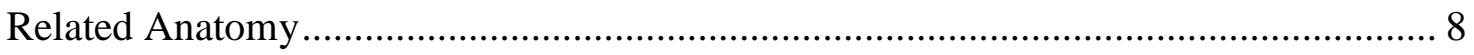

Review of Halstead .................................................................................... 12

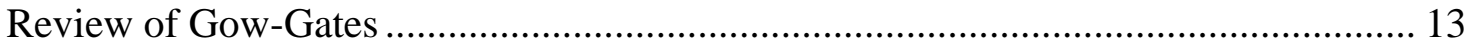

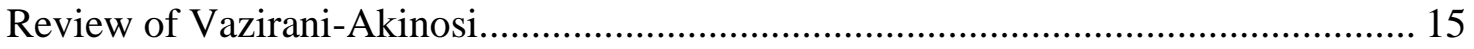

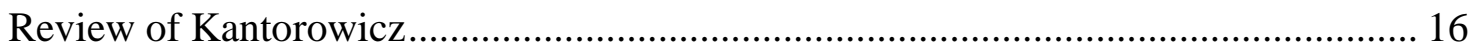




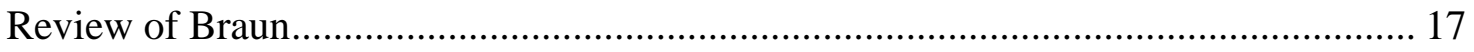

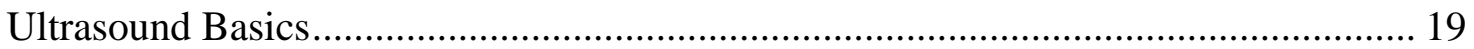

Ultrasound and Inferior Alveolar Nerve Blocks ................................................... 21

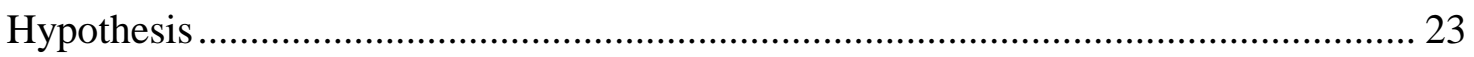

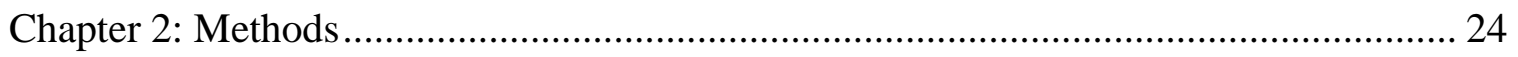

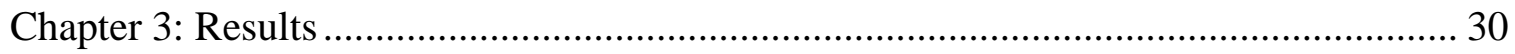

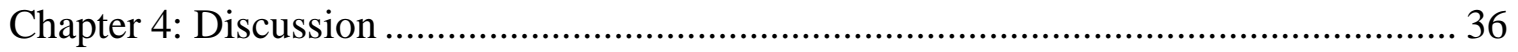

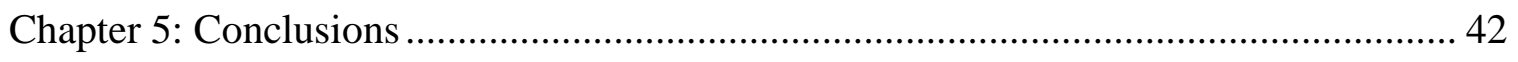

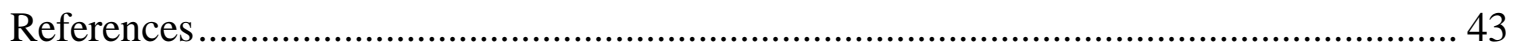




\section{List of Tables}

Table 1. Physiochemical and clinical properties of local anesthetics .............................. 5

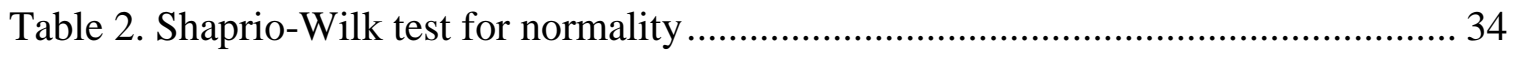

Table 3. Direct F-ratio test for homogeneity of variances (width) ................................ 34

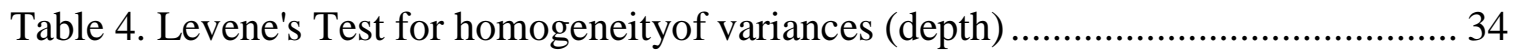




\section{List of Figures}

Figure 1. Sodium channels and local anesthesia..................................................... 3

Figure 2. Anatomy of the mandibular division of the trigeminal nerve ........................ 10

Figure 3. Boundaries of the pterygomandibular space …........................................... 12

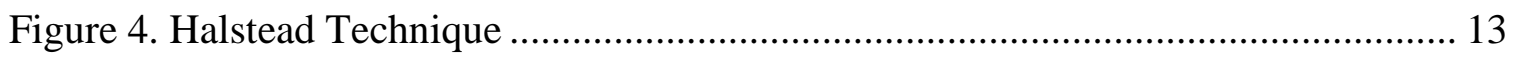

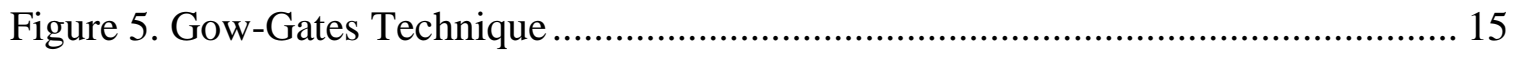

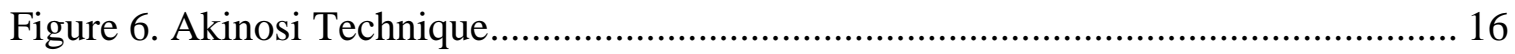

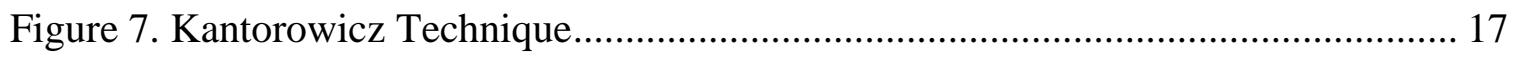

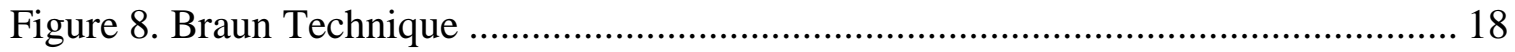

Figure 9. Image of local anesthetic distribution................................................. 31

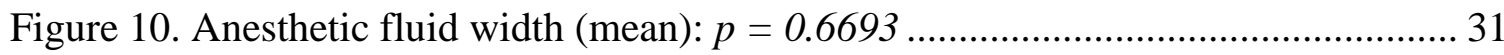

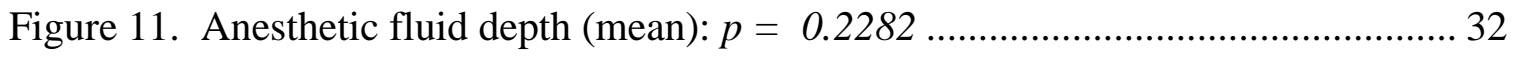

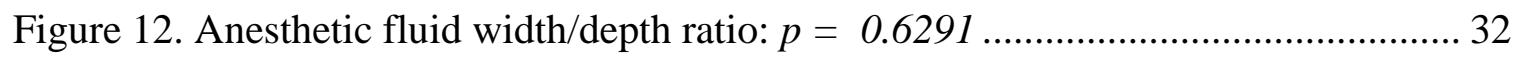

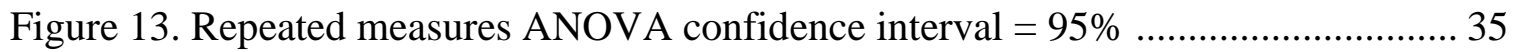




\section{Chapter 1: Introduction}

\section{$\underline{\text { Local Anesthesia }}$}

The ability to provide local anesthesia and allow for patients to undergo surgical treatment without general anesthesia is one of the greatest services that can be provided in medicine and dentistry. The inferior alveolar nerve block, the most commonly used nerve block in dentistry, has a reported failure rate of pulpal anesthesia as high as $20 \%{ }^{1}$. When compared to other blocks in medicine this is very high. The desire to improve this failure rate is ongoing and this study uses ultrasonography and an extra-oral inferior alveolar block technique to look to improve the success of the inferior alveolar nerve block.

\section{$\underline{\text { Literature Review }}$}

Local anesthetics are a group of molecules with the ability to prevent pain without inducing loss of consciousness ${ }^{1}$. Their discovery allowed for completion of medical and dental procedures easily and without pain. Local anesthetics work by preventing the generation and conduction of a nerve impulse. Nerves carry messages from one region of the body to another in the form of electrical action potentials: these are de-polarizations of the nerve cell membrane that result from a brief increase in the cell-membrane 
permeability to sodium ions $\left(\mathrm{Na}^{+}\right)$. Action potentials are initiated by chemical, thermal, mechanical or electrical stimuli. Nerves have a resting membrane potential of $-70 \mathrm{mV}$, which is achieved by establishing differing concentrations of ions on either side of the cell membrane ${ }^{1}$. A stimulus results in the increase of $\mathrm{Na}^{+}$ions within the nerve cell creating an area of less negative membrane potential or depolarization of the membrane. Once the electrical potential reaches a critical level a rapid phase of localized depolarization occurs, thus reaching the threshold potential to create an action potential. This action potential stimulates neighboring areas to depolarize and in this way the electrical activity spreads along the neural axon. To return to baseline, active reversal of the electrical potential and ion movement across the nerve membrane occurs, a process known as re-polarization of the membrane ${ }^{1}$. Local anesthetics work by binding to specific receptors on the sodium channel and thereby preventing the movement of $\mathrm{Na}^{+}$ intracellularly and the subsequent generation of an action potential (Figure 1). 


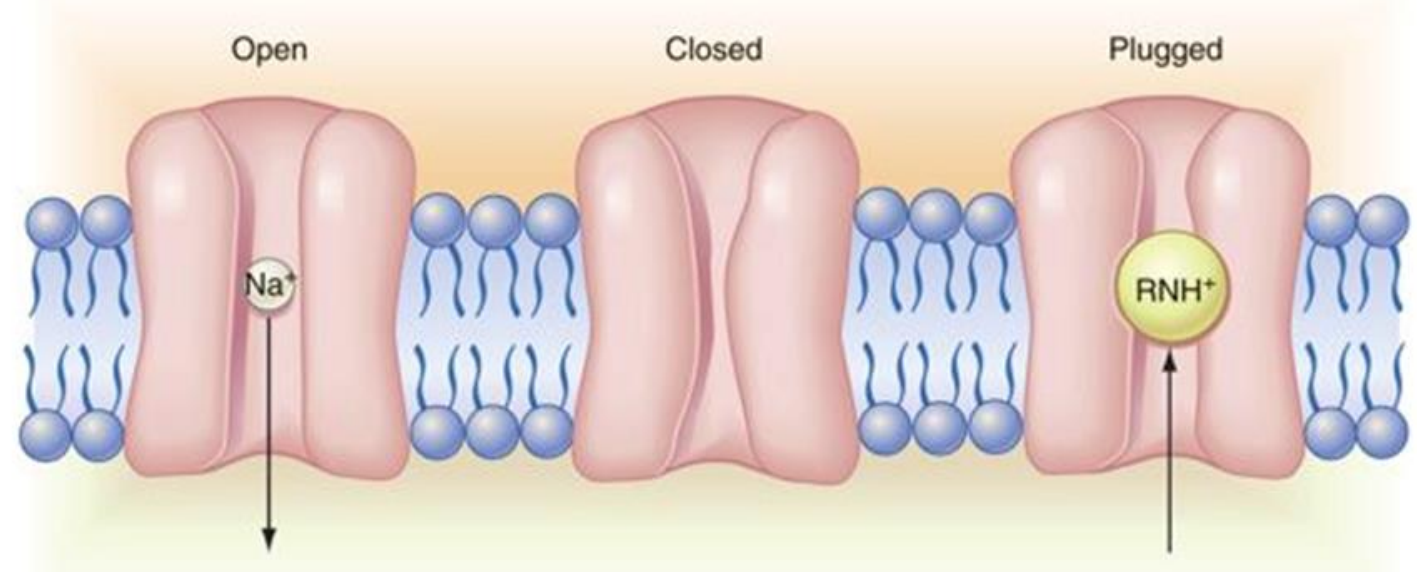

Figure 1. Sodium channels and local anesthesia

(Diagram from Malamed SF. Handbook of local anesthesia. 5th ed. St. Louis: Mosby Year Book; 2004. 15)

Three main components make up local anesthetics: an aromatic group, an intermediate chain, and a secondary or tertiary amine ${ }^{1}$. All local anesthetics are amphipathic; possessing lipophilic and hydrophilic components. The aromatic chain is the lipophilic region of the molecule. The lipophilic nature allows local anesthetics to cross cell membranes ${ }^{1}$. The hydrophilic region, the amino derivative, confers the watersoluble property ${ }^{1}$. The intermediate chain of a local anesthetic determines the classification of the anesthetic as either an amide or an ester. The intermediate chains vary in their paths of metabolism; ester-linked local anesthetics are metabolized by plasma pseudocholinesterases where amide-linked local anesthetics are metabolized by 
P-450 enzymes in the liver ${ }^{1}$. The ester-linked local anesthetics have also been associated with allergic reactions secondary to its metabolism to p-aminobenzoic acid (PABA) ${ }^{1}$. Many local anesthetic solutions also contain vasoconstrictors such as epinephrine, norepinephrine, and levonordefrin. The vasoconstrictors activate the alpha-1 receptors found on the smooth muscle in many vascular beds leading to local or regional vasoconstriction. Vasoconstriction reduces the blood flow within the region of local anesthetic delivery and results in a longer retention of the local anesthetic in the area of administration ${ }^{1}$. Local anesthetics clinical properties are dependent on the physiochemical properties of each compound. A summary of some of the more commonly used local anesthetics is provided (Table 1). 


\begin{tabular}{|c|c|c|c|c|c|c|c|c|}
\hline $\mathrm{Rx}$ & $\begin{array}{l}\mathrm{pK} \\
\mathrm{a}\end{array}$ & $\begin{array}{l}\text { Rate of } \\
\text { Onset }\end{array}$ & $\begin{array}{l}\text { Relativ } \\
\text { e } \\
\text { Potenc } \\
\text { y }\end{array}$ & $\begin{array}{l}\text { Duration } \\
\text { of } \\
\text { anesthesi } \\
a+\text { epi }\end{array}$ & Class & $\begin{array}{l}\text { Half- } \\
\text { life } \\
\text { (hours } \\
\text { ) }\end{array}$ & $\begin{array}{l}\text { Max } \\
\text { dose + } \\
\text { epi } \\
\text { (mg/kg } \\
\text { ) }\end{array}$ & $\begin{array}{l}\text { Max } \\
\text { dose - } \\
\text { epi } \\
\text { (mg/kg } \\
\text { ) }\end{array}$ \\
\hline Lidocaine & 7.8 & Fast & 2 & Moderate & $\begin{array}{l}\text { Amid } \\
\mathrm{e}\end{array}$ & 1.6 & 6.6 & 4.4 \\
\hline $\begin{array}{l}\text { Mepivicain } \\
\mathrm{e}\end{array}$ & 7.7 & Fast & 2 & Moderate & $\begin{array}{l}\text { Amid } \\
\mathrm{e}\end{array}$ & 1.9 & 6.6 & 6.6 \\
\hline Prilocaine & 7.8 & Fast & 2 & Moderate & $\begin{array}{l}\text { Amid } \\
\mathrm{e}\end{array}$ & 1.6 & 6.0 & 6.0 \\
\hline Bupivicaine & 8.1 & $\begin{array}{l}\text { Mediu } \\
\mathrm{m}\end{array}$ & 8 & Long & $\begin{array}{l}\text { Amid } \\
\mathrm{e}\end{array}$ & 3.5 & 1.3 & \\
\hline Articaine & 7.8 & Fast & 2 & Moderate & $\begin{array}{l}\text { Amid } \\
\mathrm{e}\end{array}$ & 0.5 & 7.0 & \\
\hline
\end{tabular}

Table 1. Physiochemical and clinical properties of local anesthetics

(Table data obtained from: Malamed SF. Handbook of local anesthesia. 5th ed. St. Louis: Mosby Year Book; 2004. 56-81.)

The rate of onset of the local anesthetic is dependent on its $\mathrm{pK}_{\mathrm{a}}$ value $^{1}$ (the negative $\log$ of its $\mathrm{pH}$ value). The $\mathrm{pK}_{\mathrm{a}}$ of a solution is the $\mathrm{pH}$ at which $50 \%$ of the agent exists in the ionic form and $50 \%$ exists in the non-ionic form ${ }^{1}$. The non-ionic form is the component that crosses more readily the bi-lipid cell membrane. A basic solution (most local anesthetic solutions are weak bases) with a higher $\mathrm{pKa}$ will contain a higher percent of ionized (dissociated) molecules when placed in a normal physiological environmental $\mathrm{pH}$ of 7.4; this will have a slower speed of onset. Basic solutions with a lower $\mathrm{pK}_{\mathrm{a}}$ will have a faster onset since more of the solution will be in the non-ionic form. The potency 
of the local anesthetic is based on its lipid solubility ${ }^{1}$. Increased lipid solubility allows for the molecule to cross the nerve cell lipid-membrane. By being able to cross the cell membrane readily, a lower volume is needed to prevent conduction blockade making the local anesthetic more potent. After a local anesthetic penetrates the membrane the amine portion of the molecule binds itself at the receptor site within the $\mathrm{Na}^{+}$channel ${ }^{1}$. Finally, the degree of protein binding influences the duration of action: those possessing a high level of protein binding tend to exhibit a longer activity. Local anesthetics, which have a greater degree of protein binding, attach more securely to the receptors within the $\mathrm{Na}^{+}$ channel leading to a longer duration of action ${ }^{1}$.

The local anesthetic used in our study was $2 \%$ lidocaine hydrochloride with 1:100,000 epinephrine; packaged in $1.8 \mathrm{~mL}$ cartridges, and marketed in North America under the name Xylocaine (Dentsply Pharmaceutical, York, PA). Xylocaine is an amide anesthetic, with a lidocaine concentration of $20 \mathrm{mg} / \mathrm{mL}$, an epinephrine concentration of $10 \mu \mathrm{g} / \mathrm{mL}$. This is one of the most commonly used local anesthetic solutions. It has a highly desirable safety record. The accompanying information sheet describes the maximum dosage of lidocaine with epinephrine as $7.0 \mathrm{mg} / \mathrm{kg}$, not to exceed a dose of $500 \mathrm{mg}$ for adults and $3.2 \mathrm{mg} / \mathrm{kg}$ for children. Its rate of onset is $2-3$ minutes, which is rapid secondary to its $\mathrm{pK}_{\mathrm{a}}$ of 7.8. It has a half-life of 90 minutes. It is a pregnancy class $\mathrm{B}$ drug and is safe to use on gravid patients. Although it is a very safe drug adverse reactions can occur. Common adverse reactions are most commonly related to overdose, and leading to both central nervous (CNS) and cardiovascular effects ${ }^{1}$. These are the result of depressing excitable membranes; which include both the CNS and myocardium. 
Early CNS signs of an overdose are generalized cortical sensitivity with patients becoming anxious, agitated, and restless. With further increases in dosing patients may develop confusion, disorientation, twitching, tremors and eventually tonic-clonic seizures ${ }^{1}$. CNS depression follows and finally the patient may become unconscious and go into respiratory arrest. The cardiovascular system (CVS) is less sensitive to sodium channel blocking effects of local anesthetics and is not clinically affected until sometime after manifestation of CNS effects are present. CVS effects are typically depressant in nature and include myocardial depression, bradycardia, cardiac arrhythmias, hypotension, cardiovascular collapse and cardiac arrest ${ }^{1}$. Other signs that have been reported include nausea, vomiting, chills, miosis, and tinnitus. Management of local anesthetic toxicity is based on the severity and rapidity of the reaction. Hypotension and seizure must be treated with usual methods. There is evidence that early administration of an anticonvulsant such as diazepam can help prevent seizures from occurring. ${ }^{1}$

Adverse reactions secondary to administration of vasoconstrictors, specifically epinephrine, include anxiety, palpitation, headache, tachycardia, and hypertension ${ }^{1}$. All of these reactions are rare and most often are the result of rapid intravascular injections. Inadvertent intravascular injections are best avoided by employing a good aspiration technique to confirm that needle placement is not intravascular prior to administration of local anesthetic. The total dose of epinephrine given to patients with history of compromised cardiac status should be limited to 40ug. ${ }^{1}$ 


\section{$\underline{\text { Related Anatomy }}$}

In dentistry the most commonly used technique for anesthetizing the mandibular teeth and much of the surrounding soft tissue is to block the inferior alveolar nerve (IAN). The IAN block is essential for all invasive procedures in the mandible including manipulation of both hard and soft tissues. The inferior alveolar nerve is a branch of the third division of the trigeminal, fifth cranial nerve. The trigeminal nerve $(\mathrm{CNV})$ has a large sensory root that carries the majority of the sensory innervation from the soft tissues, bone and teeth of the oral cavity. It also has a smaller motor root that innervates the muscles of mastication. It exits the antero-lateral surface of the pons as a large sensory root and small motor root ${ }^{3}$. These roots continue forward out of the posterior cranial fossa and into the middle cranial fossa by passing over the petrous part of the temporal bone. In the middle cranial fossa the sensory root expands into the trigeminal ganglion, which contains cell bodies for the sensory neurons in the trigeminal nerve. This ganglion rests in the trigeminal depression in the anterior aspect of the petrous part of the temporal bone ${ }^{3}$. Arising in from the anterior border of the ganglion are the three terminal divisions: the ophthalmic, maxillary and mandibular.

The mandibular nerve (V3) is the largest of the three divisions and exits the skull base through the foramen ovale. Regions where the trigeminal gives off branches include: the undivided, the anterior, and the posterior divisions ${ }^{3}$. The branches of the undivided portion of $\mathrm{V} 3$ are: the meningeal branch that supplies the mastoid air cells and dura mater and medial pterygoid nerve, that supplies the tensor veli palatine and tensor tympani. The branches from the anterior division include the long buccal nerve, the 
deep temporal nerves, and the lateral pterygoid nerves. The long buccal nerves gives sensation to the skin of the cheek, the buccal gingiva of the mandibular molars and mucobuccal fold in the region. The deep temporal and lateral pterygoid nerves provide motor innervation to the muscles of mastication including the temporalis, masseter, medial and lateral pterygoid muscles. The posterior division branches into the auriculotemporal, lingual, and inferior alveolar nerves (Figure 3). The auricular temporal nerve provides sensory secretor and vasomotor to the parotid gland as well as supplies skin with sensation over the following branches of the facial nerve: zygomatic, buccal, and marginal mandibular. The lingual nerve provides sensation and taste to the anterior $2 / 3^{\text {rds }}$ of the tongue, as well as the floor of mouth and gingiva on the lingual of the mandible. The inferior alveolar nerve provides sensory formation for all mandibular teeth, sensation of the skin of the chin as well as the mucous membranes of the lower lip. 


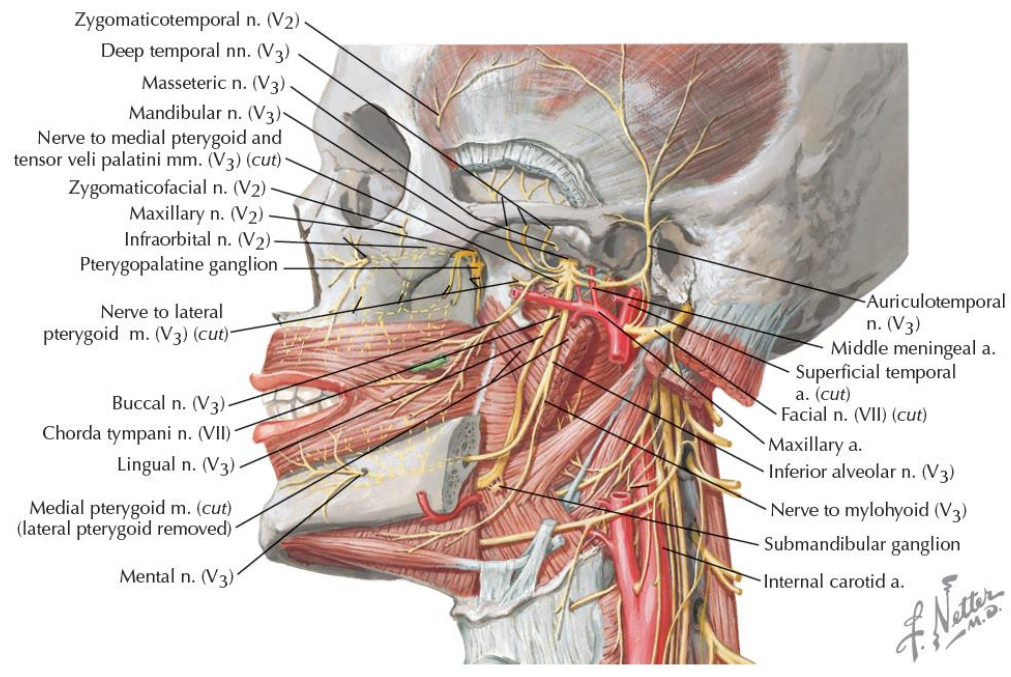

Figure 2. Anatomy of the mandibular division of the trigeminal nerve

(Diagram from Norton, NS. Netter's Head and Neck Anatomy for Dentistry 2nd ed. Elsevier Philadelphia, 2012.)

The course of the inferior alveolar nerve is such that it descends medial to the lateral pterygoid muscle and lateral and posterior to the lingual nerve between the sphenomandibular ligament and the medial aspect of the ramus ${ }^{3}$. The inferior alveolar nerve then enters the mandibular ramus at the level of the mandibular foramen. The inferior alveolar artery and vein travel just anterior to the $\mathrm{IAN}^{3}$. The mylohyoid nerve branches from the inferior alveolar nerve before the nerve enters the mandibular canal. It provides sensory innervation to skin around the mental protuberance and motor function to the mylohyoid muscle and anterior belly of the digastric. Just superior to the location of the mandibular foramen within the pterygomandibular space local anesthesia is delivered to accomplish the IAN block ${ }^{1}$. 
The pterygomandibular space is bounded anteriorly by the buccal space, posteriorly by the parotid gland and fusion of the parotidomasseteric fascia (Figure 3). Its lateral aspect is the ascending ramus of the mandible with its medial boundary being the medial pterygoid muscle. The superior border is the pterygoid muscle and the inferior border is the inferior border of the mandible ${ }^{4}$. The pterygomandibular space contains the lingual, mylohyoid, and inferior alveolar nerves as well as the inferior alveolar artery, vein, and the sphenomandibular ligament. The Vazirani-Akinosi technique is described to fill the pterygomandibular space and thus bathing the inferior alveolar, lingual and mylohyoid nerves with anesthetic ${ }^{2}$. 


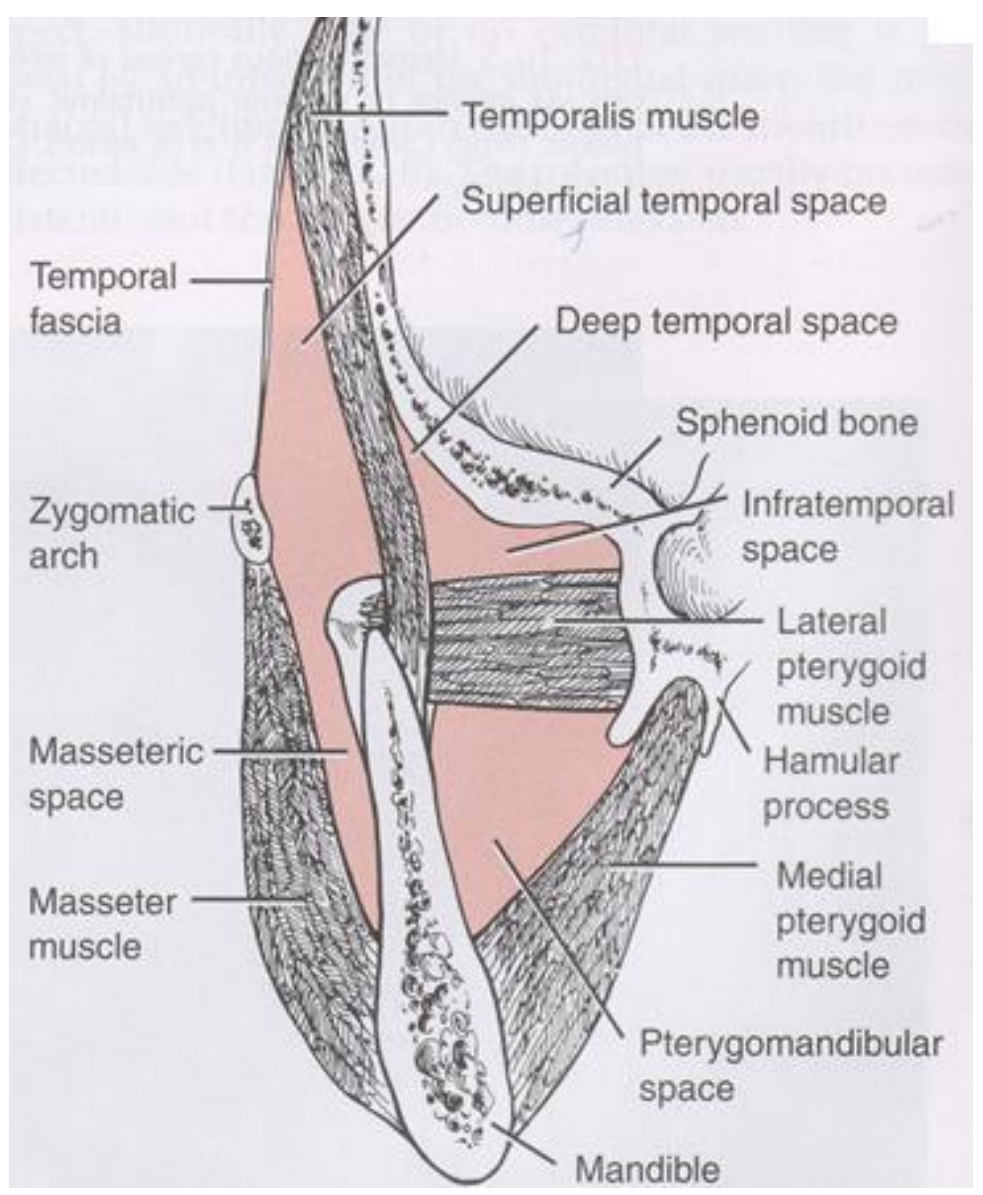

Figure 3. Boundaries of the pterygomandibular space

(Diagram obtained from: http://www.surgical-

dentistry.info/files/Spaces_of_the_Mandibular_Ramus.JPG)

\section{$\underline{\text { Review of Halstead }}$}

The most common technique to anesthetize the inferior alveolar nerve is the Halstead technique. This approach attempts to deliver local anesthesia along the inferior alveolar nerve within the pterygomandibular space prior to entering the mandibular 
foramen. This technique requires identification of three landmarks: the coronoid notch, ptergyomandibular raphe and the occlusal plane of the mandibular posterior teeth ${ }^{1}$. The height of the injection is $6-10 \mathrm{~mm}$ above the occlusal plane. The needle insertion point is 3/4 the distance from the coronoid notch posteriorly to the pterygomandibular raphe. The barrel of the needle should be at the level of the premolars on the contralateral side (Figure 4). With this injection the needle must be advanced until bone is palpated. This depth is typically $20-25 \mathrm{~mm}^{1}$. Aspiration is performed to confirm the tip of the needle is not located intravascularly and the local anesthetic is delivered ${ }^{1}$.

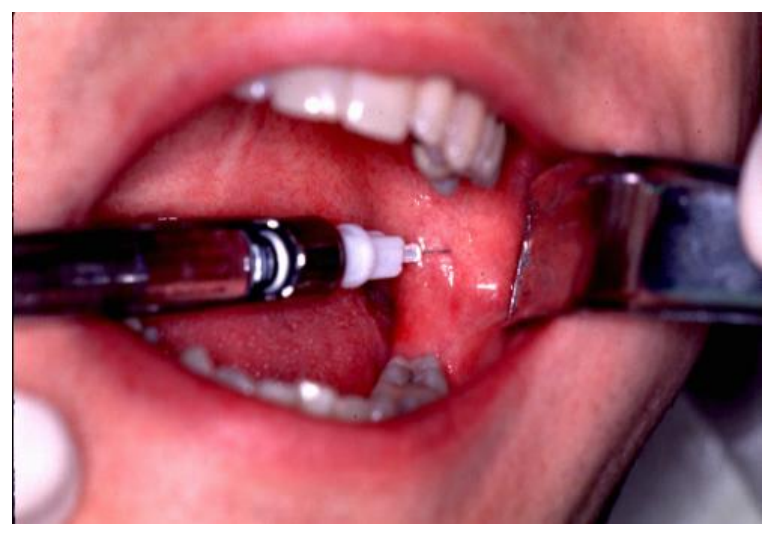

Figure 4. Halstead Technique

(Diagram from Malamed SF. Handbook of local anesthesia. 5th ed. St. Louis: Mosby Year Book; 2004. 232)

\section{$\underline{\text { Review of Gow-Gates }}$}

The Gow-Gates technique blocks all oral sensory branches of the mandibular nerve with one injection. This technique has success rates reported to be as high as $95 \%$ 
for lip numbness ${ }^{1}$. The injection site is the latero-anterior surface of the condyle with the goal of the needle insertion to just below the insertion of the lateral pterygoid muscle ${ }^{5}$. One study reports that the blood vessels on the latero-anterior surface of the condyle are much smaller than the blood vessels adjacent to the lingula, which leads to a lower likelihood of intravascular injection ${ }^{5}$. The Gow-Gates technique uses extra- and intraoral landmarks. The extra-oral landmarks include the lower border of the tragus and the corner of the mouth. The intra-oral landmark is the mesiopalatal cusp of the maxillary second molar. The area of needle insertion is on a line from the intertragic notch to the corner of the mouth, just distal to the maxillary second molar. The target area is the lateral side of the condylar neck just below the insertion of the lateral pterygoid muscle. This technique depends on the patient opening their mouth maximally and if the patient is unable to cooperate to do this maneuver the needle would be directed too far inferiorly and result in an ineffective block. Needle penetration is usually $25 \mathrm{~mm}$ in the adult patient correct position is verified when bone is contacted ${ }^{1}$. Complications with this technique have been reported to include hematoma, trismus, and temporary paralysis of CN III, IV, and VI. This technique has been shown when performed correctly to have high success rates ${ }^{5}$. This technique requires operator experience as well as patient cooperation with the requirement of having the patient open their mouth maximally (Figure 5). 


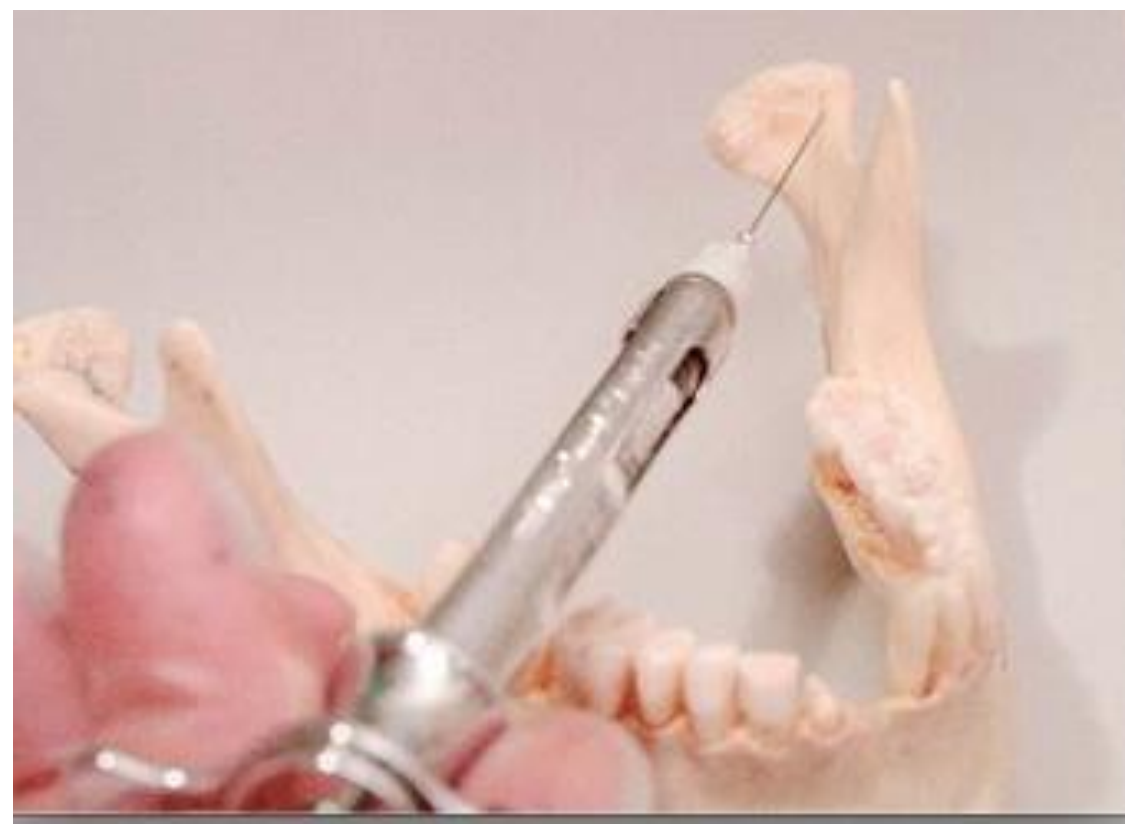

Figure 5. Gow-Gates Technique

(Diagram from Malamed SF. Handbook of local anesthesia. 5th ed. St. Louis: Mosby Year Book; 2004. 239

\section{$\underline{\text { Review of Vazirani-Akinosi }}$}

This technique is a closed-mouth technique, which reports its benefit is the ease of administration and rapid onset of anesthesia. The needle is positioned at the level of the maxillary marginal gingiva and with the barrel parallel to the maxillary occlusal plane. The syringe is advanced and the needle penetrates the tissues in the embrasure between the vertical ramus and maxillary tuberosity (Figure 6). The needle tip enters the pterygomandibular space to a depth of $2.5-3 \mathrm{~cm}$ where 1.5 to $2.0 \mathrm{ml}$ of anesthetic solution is then slowly deposited ${ }^{1}$. 


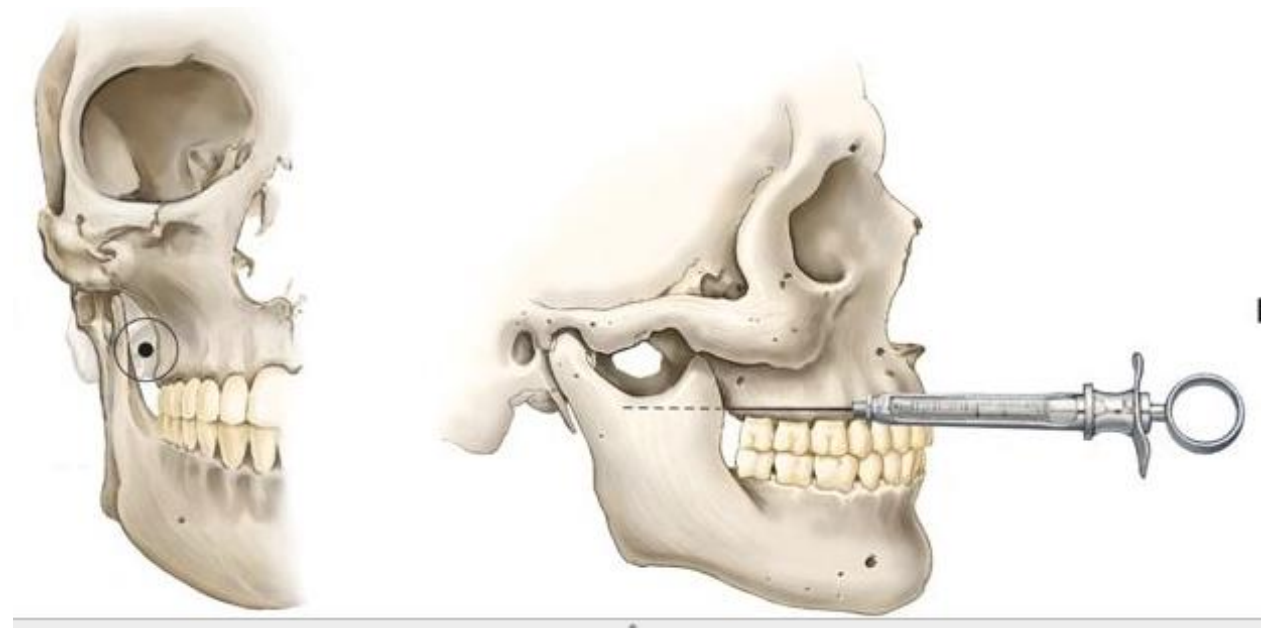

Figure 6. Akinosi Technique

(Diagram from Malamed SF. Handbook of local anesthesia. 5th ed. St. Louis: Mosby Year Book; 2004. 244)

\section{$\underline{\text { Review of Kantorowicz }}$}

This is a closed-mouth, extra-oral technique (Figure 7). A 25-gauge needle is inserted medial to the body of the mandible. One to one and a half $\mathrm{cm}$ anterior to angle of the mandible but posterior to the antegonial notch to stay posterior to the facial vessels. The needle is inserted $4.5 \mathrm{~cm}$ and inserted along the medial side of the mandibular ramus parallel to the posterior border. Aspiration is performed and then anesthetic is delivered ${ }^{6}$. 

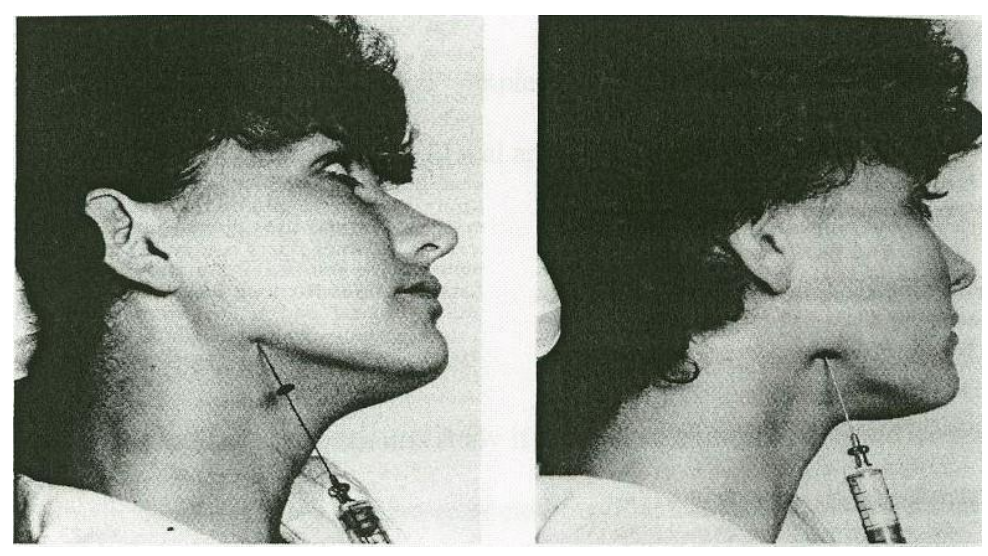

Figure 7. Kantorowicz Technique

(Diagram from Schmelzle, Rainer. Extraoral Injections; Technique and Medication.

Munich: Hanser; 1986: 74-75)

\section{$\underline{\text { Review of Braun }}$}

This extra-oral closed mouth technique has the goal of delivering local anesthesia to the third division of the trigeminal nerve just shortly after it exits out of the foramen ovale. The zygomatic arch is palpated and the halfway point of the arch is identified. A needle is advanced, perpendicular to skin, directed towards the lateral pterygoid plate. Depth has been reached once bone is encountered. This distance is then marked with a skin marker on the surface of the protruding needle. The needle is partially withdrawn and redirected posteriorly at an angle of 30 degrees and advanced until the previous marked 
depth is reached. The needle tip will be adjacent to the foramen ovale (Figure 8). To ensure that the needle is not intravascular, aspiration is performed. Because of close proximity of internal carotid artery the needle tip is rotated 90 degrees and a second aspiration is performed. If both are negative then local anesthetic is delivered ${ }^{6}$.
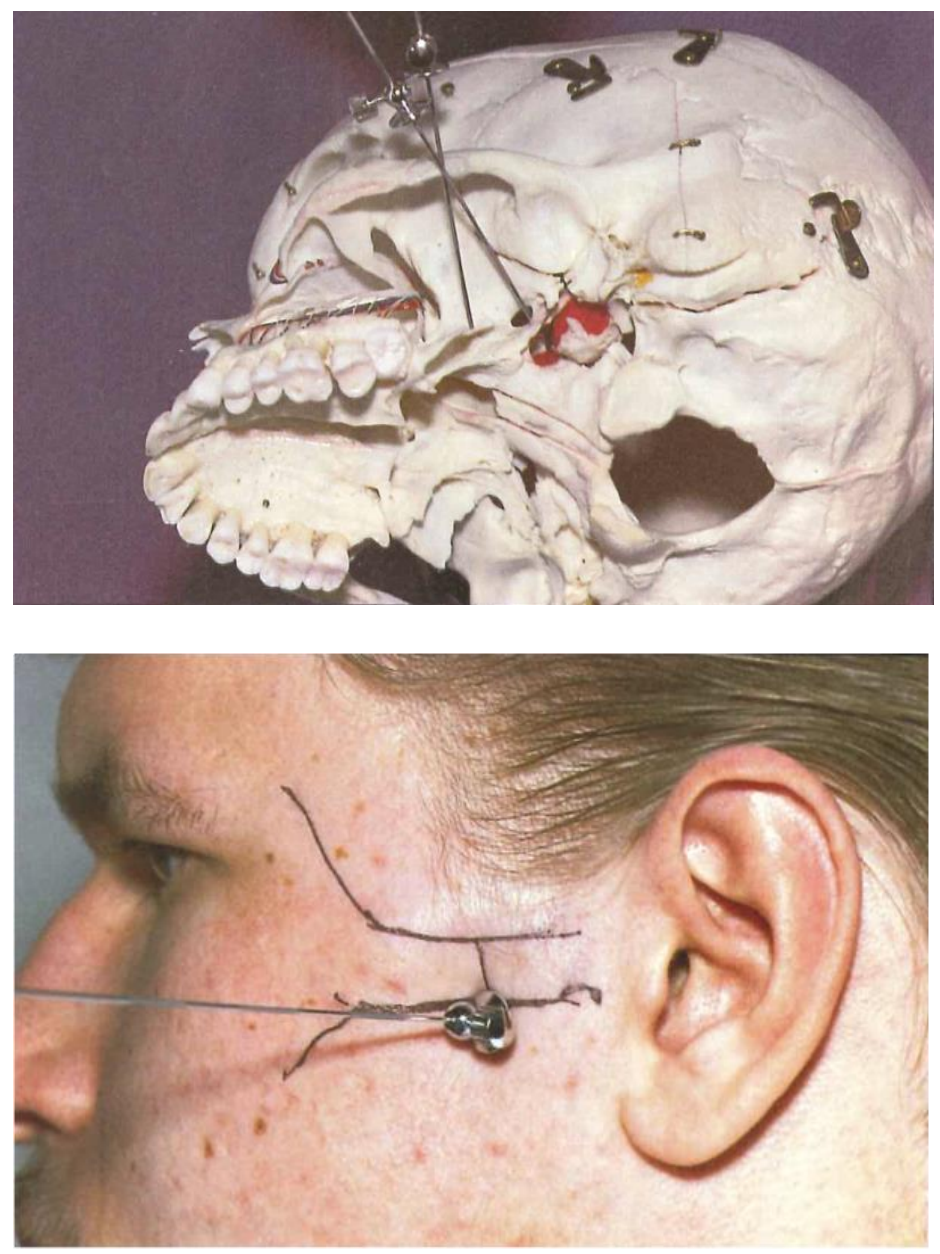

Figure 8. Braun Technique

(Diagram from Schmelzle, Rainer. Extraoral Injections; Technique and Medication. Munich: Hanser; 1986: 75) 


\section{$\underline{\text { Ultrasound Basics }}$}

Ultrasound technology in medicine continues to be an area of exploration due to being non-invasive, inexpensive and a painless diagnostic tool for soft tissue imaging. Ultrasound is a mechanical energy that is transmitted through a medium. These sound waves exert pressure on the medium, which causes periodic changes by causing molecules to oscillate around their mean or average positions. Medical ultrasound transmits ultrasound waves into the patient's body and the echoes of those waves are processed and displayed as an image. Different densities of tissues in the body absorb different amounts of energy and these differences are expressed as different shades of gray in the image. Energy is reflected back to the transducer when the wave hits different tissue densities within the body. The strength of signal is related to the tissue density ${ }^{7}$. Highest amplitude signals are white and lowest amplitude signals are black. When an image appears whiter it is termed hyperechoic and the darker the image appears it is hypoechoic ${ }^{7}$. Medical ultrasound does not allow imaging through bones or air; therefore, bone and air appear black on ultrasound imaging and are hypoechoic.

The transducer is a device that converts a signal in one form of energy to another form of energy. It is composed of one or more elements of piezoelectric material (crystals). Ultrasound transducers convert voltage impulses into ultrasound waves into the body and converts returning echoes into voltages ${ }^{7}$. Transducers are optimized to a particular frequency based on the piezoelectric crystal with a particular natural vibrating frequency. The propagation velocity in the transducer material and the thickness of the transducer element determines the operating frequency of the crystal ${ }^{7}$. The transducer is 
acoustically coupled to the patient by means of water-based gel that matches the transducer to the patient impedance.

Transducers that are lower frequency 1-3 MHz have better penetration and have good signal strength at greater depths. Higher frequencies of 7-10 MHz have better resolution when scanning shallower depths in the body ${ }^{7}$. Higher frequency transducers are more applicable to intra-oral scanning as the tissue depths are much shallower than other applications such as intra-abdominal or intra-vaginal scans.

The format of the transducer can also vary based on the way the piezoelectric crystals are aligned. They come in linear, curved, and sector array scanners. Adjusting the alignment of the crystals is similar to the principal that a photographer changes lenses for different distances and desired focal characteristics ${ }^{7}$. Also, similar to photography, ultrasound systems need to focus the ultrasound waves. This is done electronically by delaying the timing of the drive voltage to the elements to that all of the wavefronts arrive at the selected spatial point or focus at the same time ${ }^{7}$. The number of piezoelectric crystals also plays a role in the focusing properties of a transducer. Increasing the number of piezoelectric crystals improves the focus and improves spatial resolution ${ }^{7}$. Gain is the function which adjusts image brightness. Gain is the amplification of the electronic signal converted by the transducer on the monitor.

Although ultrasound is the second most widely used imaging technique, only secondary to x-ray, ultrasonography in the oral cavity has been limited thus far. Likely reasons include but are not limited to: bony interferences, limitations due to size of 
transducers with inability to use them intra-orally, and limited education in dental schools with regards to ultrasound technology and applications.

The intra-oral use of ultrasonography is just beginning to be explored. In the field of otolaryngology intra-oral ultrasound has been used to identify soft tissue abscesses with the most common location currently being the peritonsillar region ${ }^{8}$. Ultrasound has been used to evaluate intraoral tongue cancers and evaluation of depth of invasion ${ }^{9}$ as well as for evaluation of sialoliths ${ }^{10}$.

In other areas of medicine ultrasonography is commonly used for identification of arteries, veins, and nerves. Ultrasound is used routinely to assist in placement of central venous catheters in the internal jugular vein. They are commonly used to identify the radial artery for arterial-line placement. Ultrasound is also used in assistance in numerous nerve blocks in the assistance of regional anesthesia. The use of ultrasonography has greatly improved the success of nerve blocks in regional anesthesia elsewhere in medicine. There has, however, been very limited research in the use of ultrasonography in the assistance of inferior alveolar nerve blocks. To our knowledge there has been no research using ultrasound to measure the volume or distribution of local anesthetic in an inferior alveolar nerve block.

\section{$\underline{\text { Ultrasound and Inferior Alveolar Nerve Blocks }}$}

Two studies have been published describing the use of intraoral ultrasonography and inferior alveolar nerve blocks. Hannan et al. performed ultrasound guided needle placement to assist in inferior alveolar nerve blocks. The study included 40 subjects and 
it was found that there was no significant difference between the successes of pulpal anesthesia in the mandible when using ultrasound guided inferior alveolar nerve blocks and the traditional technique ${ }^{11}$. The conclusion from this study was that accuracy of needle placement is not the primary reason for anesthetic failure with IAN block. In this study the IAN was not actually visualized. In this study the inferior alveolar artery was used as a surrogate marker of the nerve location ${ }^{11}$.

A study by Changpong et al. used a novel hockey stick high frequency transducer to visualize the IAN in 20 patients. They were able to visualize the fascicular appearance of the nerve. The novel probe in this study was determined to be as comfortable as a bite block. This study concluded that causes of inferior alveolar nerve block failure could be contributed to anatomical variation and blind needle placement ${ }^{12}$. There was however, in this study, no measurement of pulpal anesthesia. Introduction of a real-time ultrasoundguided approach may help reduce block failures caused by anatomic variability and misdistribution of local anesthetic.

Our interest in improving the success rate of the inferior alveolar block and in further exploring the use of extra-oral techniques to achieve mandibular pulpal anesthesia led us to this study.

The purpose of this study was therefore, to assess two IAN block techniques by comparing the distribution of the delivered local anesthetic fluid bolus using ultrasonography. If the Kantorowicz technique can be shown to reliably deliver local anesthesia within the ptergyomandibular space adjacent to the mandibular foramen it may achieve comparable pulpal anesthesia of mandibular teeth. Such an alternative could then 
be a valuable and routine adjunct to be taught to dental student. To our knowledge, no study has been performed comparing the distribution of delivered local anesthetic with these two methods using ultrasonography.

\section{$\underline{\text { Hypothesis }}$}

Our null hypothesis is that there will be no difference between the distribution of local anesthetic between the Halstead and Kantorowicz techniques. 


\section{Chapter 2: Methods}

Seventeen Healthy ASA I and II patients older than 18 years of age presenting to the Ohio State University College of Dentistry with fully dentate mandibles, who required the extraction of at least one lower left and one lower right second or third molar, and who had chosen to have their surgery with intravenous sedation or general anesthesia, were offered the opportunity to take part in this study. All patients read and signed the approved IRB consent documentation. All patients had also already consented to the necessary procedure with sedation and/or general anesthesia at a consultation appointment that occurred prior to the planned procedure and their introduction to the study.

The numbers 1-80 were randomly arranged and then sequentially assigned to participants in the study as they enrolled. Patients receiving an odd number were in group A and patients with an even number were in group B. Patients in group A received the Kantorowicz technique on the right and the Halstead technique on the left. Patients in group B received the same blocks but on opposite sides. This was done to eliminate any advantage the operator may have on working on one particular side. The volume used for the block on each side was set to $3.0 \mathrm{ml}$ of local anesthetic. The operator performing the local anesthetic blocks (SW) was the same for all study participants and is an oral and 
maxillofacial surgery resident who has performed hundreds of inferior alveolar nerve blocks.

The patients were sedated/anesthetized either using midazolam or propofol. For deposition of local anesthesia using the Kantorowicz technique, the previously described technique to deposit local anesthesia in the pterygomandibular space was performed. Just prior to depositing local anesthesia the ultrasound transducer was placed in the patient's mouth and the mandibular ramus, inferior alveolar nerve, the buccinator, and the pterygomandibular spaces were identified. The transducer used was 7L3 high frequency linear transducer set at a frequency of $7 \mathrm{MHz}$. Ultrasound examinations were performed by the same ultrasonographer (SW). The ultrasound probe was covered with a layer of echographic gel (Aquagel, HP, Palo Alto, CA, USA). It was also covered with a layer of Saran wrap. After identifying these landmarks the $3.0 \mathrm{ml}$ of local anesthetic was delivered. The images would be captured and saved. For each injection, a representative echographic image was selected: it was saved to the hard drive.

The ultrasound used in this study was an Acuson p50 (Siemens, Munich, Germany) ultrasound unit, which is able to produce high-resolution images, and according to the manufacturer, it provides excellent tissue differentiation, temporal and spatial resolution. An expert in ultrasonography was able to help train the operator and help determine the proper settings to capture the best images. Each patient's regions of local anesthetic distribution were evaluated and viewed in 2-Dimension or 2D view. This is the most commonly used view for ultrasound ${ }^{8}$. Images were then captured and saved. The transducer used in this study was a high-frequency linear probe. High frequency 
probes have a frequency of $7 \mathrm{MHz}$ or greater. The transducer used in this study was a 7L3 transducer, which is a linear wideband array transducer. It has a maximum sonographic depth of $10 \mathrm{~cm}$ and has frequency range listed from very low to very high. This probe is also used for peripheral vascular types of exams and is applicable for breast and thyroid imaging ${ }^{8}$.

The Acuson p50 works with Microsoft Windows (Microsoft ${ }^{\circledR}$, Redmond, WA) where standard software is available and comes installed with customized exams to view different types of anatomy such as cardiac, breast, and thyroid. A custom exam was developed to view soft tissue swellings of the head and neck and was based closely on the preset exams of the thyroid. The size of patient was set to medium. The frequency was set to high. The breast and thyroid exams also use the high frequency where the carotid artery exam uses a medium frequency ${ }^{8}$. The exact frequencies depend on the type of transducer connected. Maximum depth was set to a depth of $5 \mathrm{~cm}$. Increasing the depth allows the operator to view larger or deeper structures and decreasing the depth allows the operator to view shallower structures. The focus increases the resolution to a specific area to optimize the range. The primary focus was set to depth of $2.5 \mathrm{~cm}$ and 3 foci were used. The focus and distribution method are the same as the breast and thyroid presets. The frame rate decreases by increasing the number of focal zones ${ }^{8}$. The focus and distributions used were very similar to those used in breast and thyroid exams. The frequency, depth and focus were not changed between patients. The gain was adjusted for each individual and each individual injection. Adjusting time gain compensation corrects for attenuation by adjusting the amplification of returning signals, which works 
to equalize the brightness of the returning echoes. The image format was set to linear; trapezoidal is often better when trying to achieve images at greater depths.

The scanned images were then saved for later comparison of depths and widths of distribution. The depth accounted for the antero-posterior direction while the widths accounted for the medio-lateral direction. The vertical dimension could not be captured and was limited by the dentition and size of the transducer.

The local anesthetic used this study was $2 \%$ lidocaine hydrochloride with 1:100,000 epinephrine packaged in $1.8 \mathrm{~mL}$ cartridges, and marketed in North America under the name Xylocaine (Dentsply Pharmaceutical, York, PA.). This is an amide anesthetic, with a lidocaine concentration of $20 \mathrm{mg} / \mathrm{mL}$, an epinephrine concentration of $10 \mu \mathrm{g} / \mathrm{mL}$. This is one of the most frequently used and commercially available local anesthetic solutions.

To administer the extra-oral block (Kantorowicz technique) the patient's head was turned away from the designated extra-oral injection side. The posterior border, inferior border and angle of the mandible were palpated. The planned injection site was then prepped with an alcohol pad and was approximately $1 \mathrm{~cm}$ anterior to the angle of the mandible. Care was taken to stay posterior to the antegonial notch to avoid the facial vessels. Next, a 25-gauge 90 millimeter spinal needle (BD Spinal Needle, $0.51 \mathrm{~mm}$ x 8.89 cm, BD Medical Systems, Franklin Lakes, NJ) was marked with a surgical marking pen at a point 45 millimeters from the needle tip. At this mark, a 45-degree bend was made in the needle shaft, taking care to mark the bevel of the needle on the side corresponding to the plane of the bend. This bend allowed for the need to remain in close approximation 
to the medial surface of the mandible as it was advanced superiorly. The bend in the hub was both to determine the depth the needle should be inserted as well as to help keep the bevel orientation thus preventing the needle from traveling in an unintended path. The needle was then inserted at the planned insertion point. It was advanced superiorly until it contacted the inferior border of the mandible. Next, the needle was directed medially and "walked-off" the inferior border into the ptergyomandibular space. It was advanced superiorly to the $45 \mathrm{~mm}$ marker/location of the bend in the needle.

Aspiration was then performed. If the aspirate was positive the needle would be carefully repositioned. Once a negative aspiration was returned $3.0 \mathrm{~mL}$ of $2 \%$ Lidocaine with 1:100,000 epinephrine were injected.

The Halstead technique was used for the opposite side as follows. The patient's mouth was opened and a bite block was placed on the contralateral side. The anterior border of the mandibular ramus was palpated intra-orally. The point of needle entry was then through the buccal mucosa, approximately $1 \mathrm{~cm}$ above the plane of the teeth in the lower jaw, parallel to this plane and directed to appoint that was $1 / 2$ the distance between the palpated anterior and posterior borders of the ramus. Using a standard syringe and $25 \mathrm{~g}$ needle, aspiration was performed with the syringe plugger as before to confirm the needle tip was not intravascular. Three milliliters of $2 \%$ lidocaine with 1:100,000 epinephrine were injected. Following this injection the ultrasound transducer was used to capture the image of the local anesthesia bolus.

The data gathered included the captured images from the distribution of local anesthetic within the pterygomandibular space. Syngo Ultrasound Workplace software 
was used to measure the planar dimensions of the local anesthetic. The width and depth of the distribution of anesthetic was measured for all captured images. A Student's t-test was used to compare the depth, width, and ratio of depth to width of the 2 injection techniques. 


\section{Chapter 3: Results}

Using ultrasonography we confirmed the Kantorowicz technique and the traditional Halstead technique place solution into the pterygomandibular space (Figure 9).

A Student's t-test was used to compare the mean distribution of local anesthetic depth, mean width of local anesthetic, and the ratio of the depth to the width of the local anesthetic bolus between the extra-oral and intra-oral techniques. The paired Student's ttest showed there was no statistical difference between the two techniques in the distribution of the local anesthetic bolus in either mean depth, mean width, or ratio of the width to depth. The p-value for comparison of the mean local anesthetic distribution of depths was 0.2282 , for widths was 0.6693 and for the ratio width to depth was 0.2488 between intra-oral and extra-oral techniques. $95 \%$ confidence intervals are shown. (Figures 10, 11, 12). 


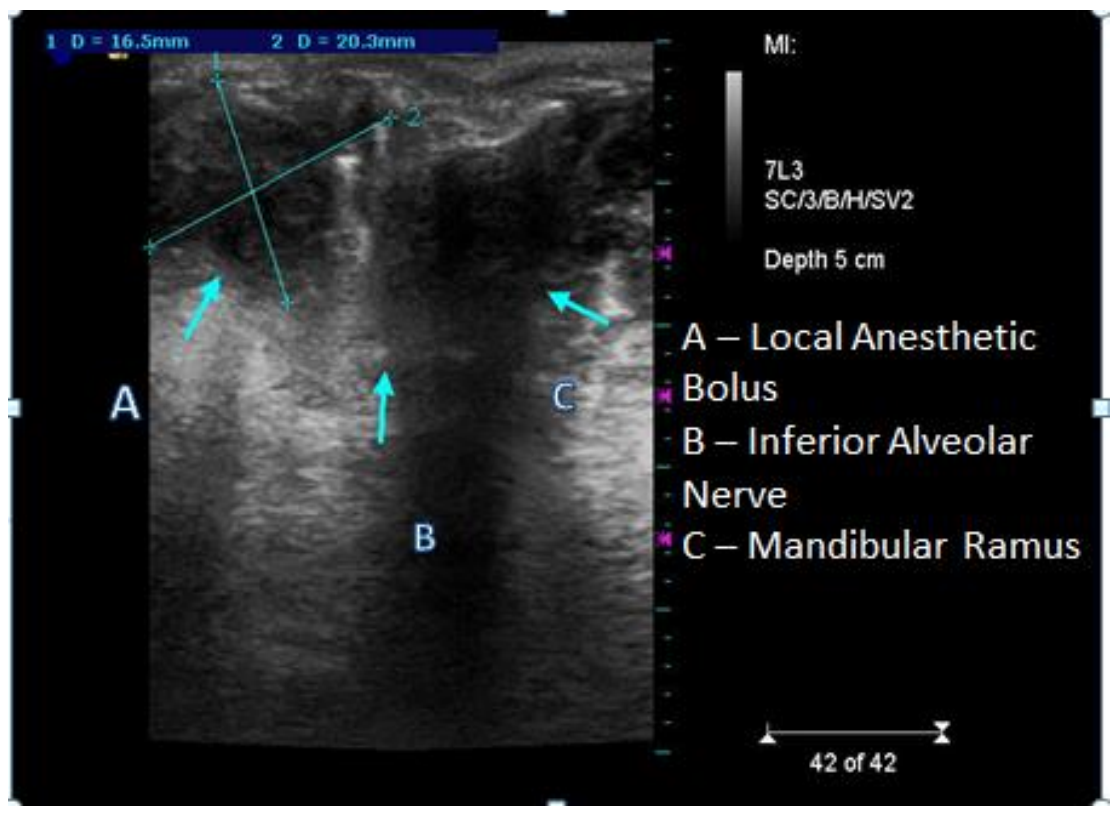

Figure 9. Image of local anesthetic distribution

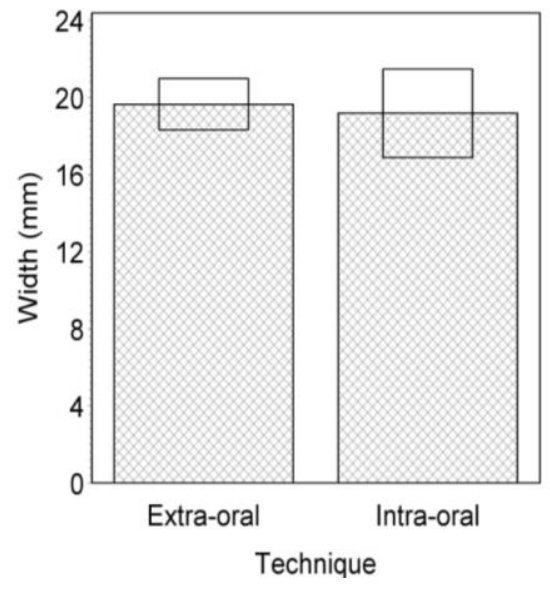

Figure 10. Anesthetic fluid width (mean): $p=0.6693$ 


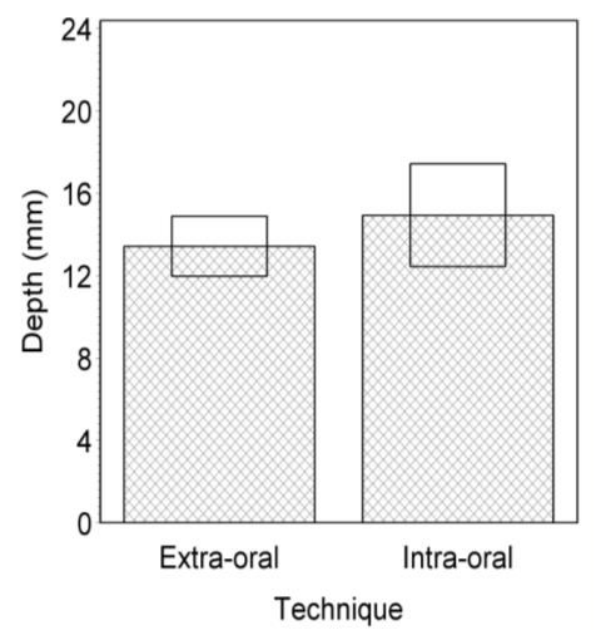

Figure 11. Anesthetic fluid depth (mean): $p=0.2282$

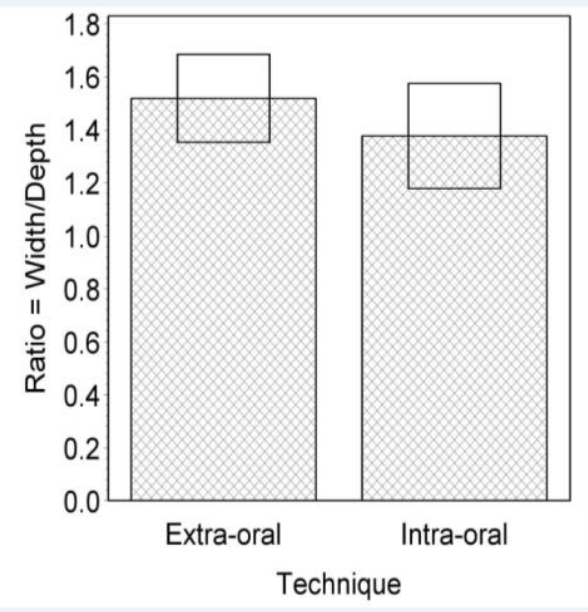

Figure 12. Anesthetic fluid width/depth ratio: $p=0.6291$

Initial evaluation of the data revealed that the mean depth distribution of the fluid boluses appeared to be more varied than the mean width. To determine which of the 
many tests for homogeneity of variances would be better used, a Shapiro-Wilk test for normality was run. This confirmed, with a p-value of 0.3546 , that the distribution of mean widths was in fact normally distributed. The p-value for the distribution of mean depths was 0.0077 , showing that the mean depths were not distributed normally. To further evaluate this variance within the distributions, a direct F-ratio test for homogeneity of variance was performed on the normally distributed widths, while the Levene's test for homogeneity of variance was performed on the not normally distributed depths. The direct F-ratio test two-tailed p-value was 0.0332 demonstrating a statistically significant amount of variance within the intra-oral distributions of widths when compared to the extra-oral distributions. The Levene's test for homogeneity of variance p-value was 0.0133, also demonstrating a statistically significant amount of variance within the intra-oral distributions of depths when compared to the extra-oral distributions. This showed that there was more variance between the distributions with the Halstead technique when compared to the Kantorowicz technique.

A repeated measures analysis of variance was also performed where both the direction (width and depth) and the techniques (intra-oral and extra-oral) are repeated in each subject. The only statistically significant effect was in direction where the p-value was $<0.01$. 


\begin{tabular}{|l|l|}
\hline Variable & P - Value \\
\hline Width & 0.3546 \\
\hline Depth & 0.0077 \\
\hline
\end{tabular}

Table 2. Shaprio-Wilk test for normality

\begin{tabular}{|l|l|}
\hline Variable & p-value \\
\hline Width & 0.0332 \\
\hline
\end{tabular}

Table 3. Direct F-ratio test for homogeneity of variances (width)

\begin{tabular}{|l|l|}
\hline Variable & p-value \\
\hline Depth & 0.0133 \\
\hline
\end{tabular}

Table 4. Levene's Test for homogeneityof variances (depth) 


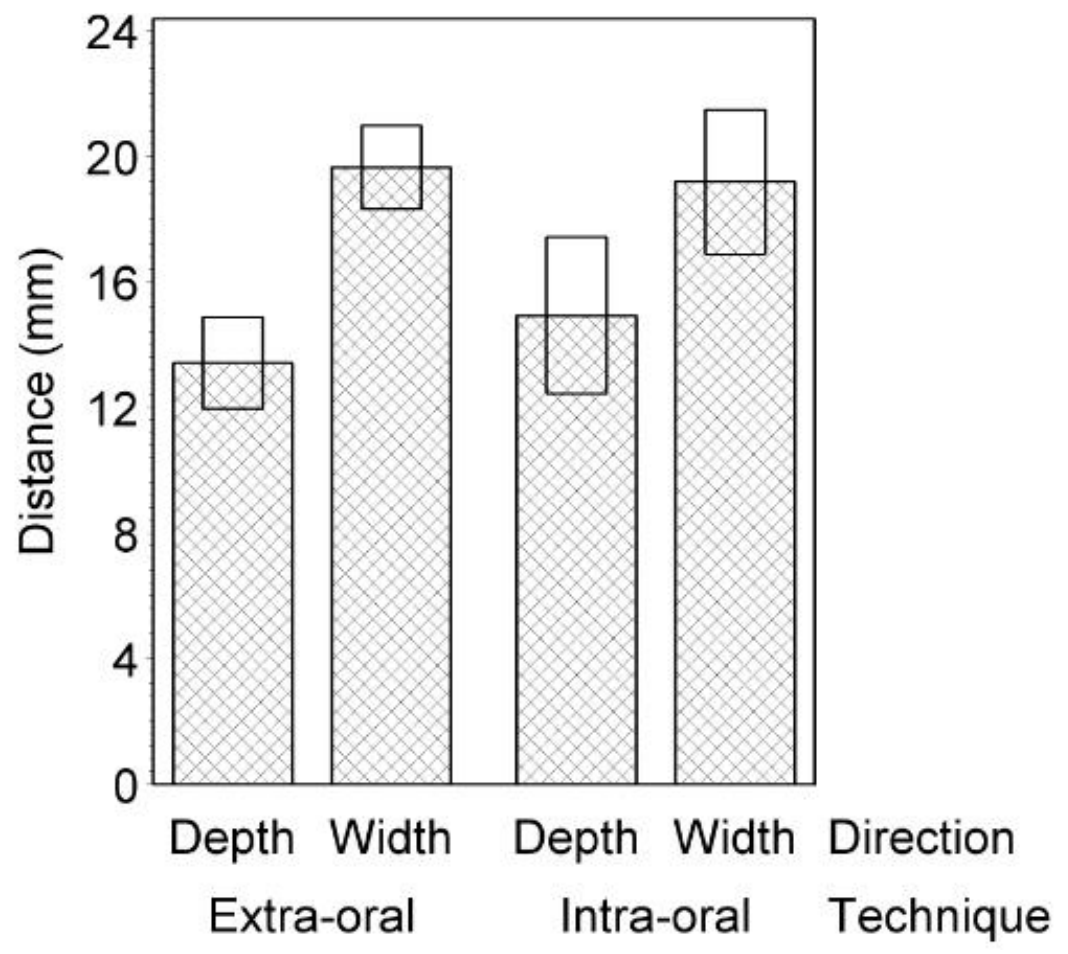

Figure 13. Repeated measures ANOVA confidence interval $=95 \%$ 


\section{Chapter 4: Discussion}

Our study showed that both the Halstead technique and Kantorowicz technique were able to deliver local anesthetic within the ptergymandibular space adjacent to the inferior alveolar nerve. Confirmation of the location and distribution of the local anesthetic was able to be visualized using 7L3 linear ultrasound transducer. The means of the distribution were the same using either technique. Our results indicate that our null hypothesis was correct; there was no significant difference in distribution when using the two techniques and comparing the mean widths and depths of the fluid bolus. It appears that the distribution of the fluid bolus was likely limited to the dimensions of the pterygomandibular space itself rather than being influenced by the direction the fluid bolus was delivered.

A repeated measures analysis of variance showed that the depth was significantly different than the width. This fluid distribution is consistent with the boundaries of the pterygomandibular space. The depth of this space is the distance from the medial pterygoid muscle to the ramus. The width of this space is bounded anteriorly by the buccal space to the parotid posteriorly. The potential width of this space is much greater than the potential depth of this space and this was demonstrated by the dimensions of the local anesthetic boluses measured in this study. 
Although we were not able to use the novel hockey-stick ultrasound probe (Ultrasonix, British Columbia, Canada) which had previously been used to identify the fascicular nature of the inferior alveolar nerve, we were able to use the high frequency 7L3 linear transducer to visualize the inferior alveolar nerve as well as identify and capture a two dimensional image of the fluid collection. Ultrasonography allowed for us to visually confirm that the fluid bolus was adjacent to the inferior alveolar nerve and canal.

As mentioned in the results section during the initial evaluation of the data it appeared that the distribution of the mean depths varied more than the distribution of the mean widths. To further evaluate this difference we needed to perform a test for homogeneity of variance. There are many tests for homogeneity of variance. To help determine which would be the most appropriate test for our data we needed to determine if the data was normally distributed.

A Shapiro-Wilks test was performed to determine if the data was normally distributed. This was used because according to the Journal of Statistical Modeling and Analytics the Shapiro-Wilk test is the most powerful normality test ${ }^{13}$. The results of this test showed that the distribution of widths was normally distributed; however the distribution of depths was not normally distributed. Since the widths were normally distributed the direct F-ratio test was an appropriate test to evaluate the homogeneity of the variance of the width dimension ${ }^{14,15}$. Because the depth data was not normally distributed common tests for homogeneity of variance including the direct F-ratio test and Bartlett's test could not be used ${ }^{16,17}$. The Levene's test is less dependent on data being 
normally distributed $^{18,19}$. Therefore this was an appropriate test for evaluation of homogeneity of variance of depths in this study.

The direct F-ratio test for homogeneity of variance showed that there was a statistically significant difference in the variance of the distribution of widths (anteroposterior distribution) of the fluid bolus between the intra-oral and the extra-oral techniques. Also, the Levene's test for homogeneity of variance also showed that there was a statistically significant difference in the variance of the distribution of the depths (medio-lateral distribution) of the fluid bolus between the two techniques. The tests for homogeneity of variance showed that there was more variance within the distributions of fluid measured following the intra-oral technique when compared to that seen after an extra-oral application.

This variance in the intra-oral technique's (Halstead) distributions may be due to the variability of the delivered fluid bolus when using this technique (i.e. the shape of pterygomandibular space changes when the patient has an open mouth). It has been previously described that the local anesthetic bolus moves in the path of least resistance within the pterygomandibular space ${ }^{20}$. The anatomy of the pterygomandibular space changes when the patient has an open mouth, and in doing so may alter the path of least resistance for the flow of the local anesthetic solution. If a relationship between mouth opening and changing fluid distribution does exist then this may contribute to the higher IAN block failure rates reported.

We also noted that locating and defining the dimensions of a fluid bolus after its administration was not always easy, a finding that may in part explain the higher variance 
seen in the intra-oral technique. The extra-oral technique permitted the observation of the fluid bolus during delivery and helped insure an accurate measurement of the local anesthetic fluid bolus.

Due to the size of the transducer, which is slightly larger than a typical small bite block, it was not possible to introduce the ultrasound probe and local anesthetic syringe simultaneously; therefore, real-time ultrasonography was prevented within the confines of this study. The novel ultrasound probe from Ultrasonix may have allowed for evaluation of the fluid bolus with real-time ultrasonography using both the intra-oral and extra-oral techniques. Unfortunately this probe was not made available for this study.

Variance of the distributions between the two-techniques may also be accounted for by fine anatomical variations between patients: these may influence the flow of solutions applied into the same space but from different directions. This may account for some of the inferior alveolar nerve block failures and warrants further research.

Other limitations of this study include that there was a small sample size of only 17 patients. No power analysis was performed because this was an initial study used only to evaluate the distributions of fluid delivered using the two IAN block techniques. There also was bias in this study as there was only one operator performing the blocks.

The Kantorowicz technique is not a technically challenging injection technique. It has been reported to have high success. Using ultrasonography this study shows that a fluid bolus of local anesthesia is delivered adjacent to the inferior alveolar nerve using this technique. 
An unpublished master's thesis study conducted by Kapitan and Prior indicated that the Kantorowicz technique was more effective than the traditional Halstead technique for achieving pulpal anesthesia ${ }^{21}$. Kapitan's study also found that the majority of patients who had a preference for either the intra-oral or the extra-oral technique preferred the extra-oral technique. Psychologists propose that because the oral cavity subconsciously represents not only a pleasure center, but also a seat of personality and identity; that procedures that are the most painful and invasive in that part of the body are the most feared and this may, in part, explain this preference ${ }^{22}$.

Along with ultrasound other techniques have been used to help identify and confirm accurate needle placement. Simon and his colleagues performed a study using a peripheral nerve stimulator to try achieve accurate needle positioning. Their conclusion was that performing an IAN block when using a nerve stimulator did not increase the success rate of achieving pulpal anesthesia when compared to the conventional block ${ }^{23}$.

A study by Vreeland et al. found that the volume $1.8 \mathrm{~mL}$ vs. $3.6 \mathrm{~mL} 2 \%$ lidocaine did not alter the success of pulpal anesthesia in the 30 adult volunteers ${ }^{24}$, future research could perhaps evaluate further the volume of fluid required to fill the pterygomandibular space and whether or not the successful filling of this space is influenced by the direction of local anesthetic administration.

Another explanation for failure to achieve pulpal anesthesia with inferior alveolar nerve blocks is the central core theory' which states that the nerves on the outside of the nerve bundle supply the molars while nerves on the inside of the nerve bundle supply the anterior teeth $^{20}$. Therefore, the ability of a local anesthetic solution to diffuse into the 
nerve trunk may be more important in achieving pulpal anesthesia then the location of delivered fluid bolus ${ }^{20}$. 


\section{Chapter 5: Conclusions}

The extra-oral technique by Kantorowicz was shown to deliver local anesthetic in an anatomical space similar to the traditional Halstead technique when assessed in two dimensions with ultrasonography.

There was no statistical difference between the means of the two fluid bolus

distributions. There was, however, more variance in the dimensions of the fluid bolus when using the Halstead technique than when using the Kantorowicz technique. 


\section{References}

1. Malamed SF. Handbook of local anesthesia. $5^{\text {th }}$ ed. St. Louis: Mosby Year Book; 2004. 27-37, 227-253

2. Haas, D. Alternative mandibular nerve block techniques: A review of the GowGates and Akinosi-Vazirani closed-mouth mandibular nerve block techniques. JADA, 2011, 142, suppl 3, 8S-12S.

3. Drake, RL et al. Gray's anatomy for students. Philadelphia: Elsevier; 2005, 748$772,815-829$

4. Miloro et al. Peterson's principles of oral and maxillofacial surgery 2 nd edition. Hamilton: BC Decker. 278

5. Gow-Gates G, Watson JE. Gow-Gates mandibular block applied anatomy and histology. Anest Prog 1989;36(4-5): 193-95

6. Schmelzle, Rainer. Extraoral Injections; Technique and Medication. Munich: Hanser; 1986: 1-75

7. Brandt, WE. Core Curriculum, The: Ultrasound. 1st edition. Lippincott Williams \&Wilkins; 2001: 1-23

8. Loock JW. A randomized trial comparing intraoral ultrasound to landmark-based needle aspiration in patients with suspected peritonsillar abscess. Clin Otolaryngol. 2013. Jun;38(3): 245-7.

9. Shintani, et al. The usefulness of intraoral ultrasonography in the evaluation of oral cancer. Int J Oral Maxillofac Surg. 2001. Apr; 30(2):139-43.

10. Cho W, Lim D, Park H. Transoral sonographic diagnosis of submandibular duct calculi. J Clin Ultrasound. 2014 Feb; 42(2)125-8.

11. Hannan L, Reader A, Nist R, Beck M, Meyers WJ. The use ofultrasound for guiding needle placement for inferior alveolar nerve blocks. Oral Surg Oral Med Oral Pathol Oral Radiol Endod1999;87:658-65. 
12. Chanpong et al. Real-time ultrasonographic visualization for guided inferior alveolar nerve injection. Oral Surg Oral Med Oral Pathol Oral Radiol, 2013, 11, 272-276.

13. Razah, N. M.; Wah Y. B. Power comparisons of Shapiro-Wilk, KolmogorovSmirnov, Lilliefors, and Anderson-Darling Tests. Journal of Statistical Modeling and Analytics, 2011, 2, 1, 21-32.

14. Markowski CA, Markowski EP. Conditions for the Effectiveness of a Preliminary Test of Variance. The American Statistician, 1990, 44, 4, 322-326.

15. Box, GP. Non-Normality and Tests on Variances. Biometrika, 1953, 40, 318-335.

16. SAS Institute Inc. Homogeneity of Variance in One-Way Models. SAS/STAT(R) 9.22 User's Guide. [Internet]. [updated 2014]. Cary, North Carolina. [cited 2014 Jan 28]. Available from: http://support.sas.com/documentation/cdl/en/statug/63347/HTML/default/viewer. htm\#statug_glm_a0000000869.htm

17. Shapiro, SS, Wilk MB. An analysis of variance test for normality. Biometrika, $1962,52,591-611$.

18. Levene Test for Equality of Variances. NIST/SEMATECH e-Handbook of Statistical Methods. [Internet] [updated 2012 Jun 27]. [cited 2014 Jan 28]. Available from: http://atomic.phys.uni-sofia.bg/local/nist-e-handbook/ehandbook/eda/section3/eda35a.htm

19. Buthmann A. Dealing with Non-normal Data: Strategies and Tools. [internet]. [updated 2010 Feb 26]. iSixSigma. [cited 2014 Jan 28]. Available from http://www.isixsigma.com/tools-templates/normality/dealing-non-normal-datastrategies-and-tools/

20. Reader A, Nusstein J, Drum M. Successful Local Anesthesia For Restorative Dentistry and Endodontics. Hanover Park: Quintesssence Books; 2011. 1-58.

21. Kapitan RA, Prior S. Trigeminal nerve blockade; a comparison of two techniques. Master's Thesis. The Ohio State University. 2006.

22. Berggren J, Meynert G. Dental fear and avoidance: causes, symptoms, and consequences. JADA 1984; 109: 247-51 
23. Simon et al. A prospective, randomized, single-blinded study of the anesthetic efficacy of the inferior alveolar nerve block administered with a peripheral nerve stimulator. Journal of endodontics, 2010, 36, 3, 429-433.

24. Vreeland et al. An evaluation of volumes and concentrations of lidocaine in human inferior alveolar nerve block. Journal of endodontics, 1989, 15, 1, 6-12. 